\title{
Myeloperoxidase (MPO), Possible Biomarker in Heart Failure
}

\author{
SORIN IOAN TUDORACHE ${ }^{1}$, BOGDAN IOAN COCULESCU², GHEORGHE MANOLE², TUDOR HARSOVESCU*, \\ MAGDALENA BIANCA TONE ${ }^{3}$, ALEXANDRA-LIGIA DINCA ${ }^{4}$ \\ ${ }^{1}$ Titu Maiorescu University Bucharest, Faculty of Medicine, 22 Dambovnicului Str., Bucharest, Romania \\ ${ }^{2}$ Colentina Hospital Bucharest, 19 Stefan Cel Mare, Bucharest, Romania \\ Titu Maiorescu University, Faculty of Medicine of Bucharest, 22 Dambovnicului, Bucharest, Romania \\ 4Medicover Hospital Bucharest, 24 Preciziei Blvd., Bucharest, Romania
}

The justification for choosing and this enzyme marker to investigate the variation in serum concentration is supported by at least two arguments: cytokine myeloperoxidase at the level of the hypocritical myocardium, with or without contractile deficiency, can be secreted by any type of component or resident in the myocardium In cardiac failure, one of the forms that responds to the oxidative stress existing in the disease is MPO secretion that occurs early after some authors even during Class I contractile myocardial deficiency (NYHA classification).

Keywords: myeloperoxidase (MPO); ejection fraction of the left ventricle; preserved systolic function; diastolic dysfunction; reactive oxygen species

Myeloperoxidase (MPO), as an oxidative stress marker, is a serum indicator that highlights the state of activation of the leukocytes involved in the development of inflammatory degenerative action in the cardiovascular apparatus, primarilyat the level of the vessels. Atthis level, irrespective of vessel topography, including coronary arteries, the circulating level of myeloperoxidase is the expression of the action of its reaction products that can affect the structure and function of HDL-cholesterol but also the activity of enzymes associated with it [1].

Starting from the scientific literature in the literature that unanimously states that oxidative stress and endothelial dysfunction are recognized as pathogenic mechanisms present not only in ischemic cardiopathy butalso in cardiac insufficiency justifies the decision to include among those whose serum-I also proposed to cause myeloperoxidase. Scientifically, it is recognized that myeloperoxidase is a marker of the inflammatory process that is pathogenic in both of these disorders. The utility of measuring the circulating level of myeloperoxidase as a marker of risk has already been demonstrated for chronic pain ischemic heart disease and is still a subject of controversial research for heart failure [2].

If in the medical literature studies of the biomarker value of MPO in cardiac insufficiency are still sporadic, in ischemic cardiopathy, the circulating values of myeloperoxidase are universally recognized as an oxidative stress indicator / marker for risk in coronary syndromes ]3].

The motivation of choosing to determine circulating MPO values in patients with ischemic cardiopathy was based on these data of universal recognition of myeloperoxidase as a biomarker in this disease but also on the need as mentioned above to have a reference criterion for the analysis of this a parameter determined by us in patients with heart failure.

\section{Experimental part}

\section{Material and method}

We constituted a study group composed of 91 patients with heart failure with a preserved ejection fraction, which presented the etiology of the myocardial inotropic deficiency the existence of only an ischemic heart disease (fig.1).

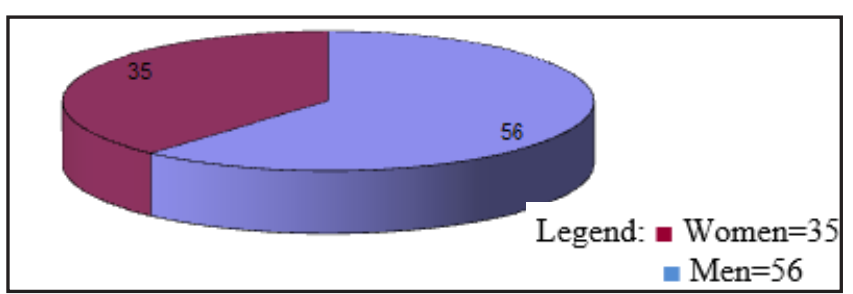

Fig. 1. The composition of the study group in relation to the sex of the patients

\section{Results and discussions}

According to a hypothesis formulated since the end of the last century, myeloperoxidase pathogenesis of cardiac insufficiency would intervene mediating the relationship of activated leukocytes to myocardial contractile deficit. The developed action is a determinism, because the permanetic activation of the white elements leads to the progression of heart failure $[4,5]$.

Starting from this pathogenic mechanism by which myeloperoxidases interfere in the development of cardiac insufficiency, especially in the form of etiological deficiency of myocardial irrigation, we have proposed in our study to investigate the circulating level and the variation of this enzyme in the 91 patients diagnosed with such a disease.

In the caseload of the whole target group consisting of patients with cardiac insufficiency due to ischemic cardiopathy, the mean serum MPO concentration was 351 $\pm 24.75 \mathrm{IU} / \mathrm{L}$ and those with the $383 \pm 14.25 \mathrm{IU} / \mathrm{L}$ (mean serum activity over the entire target group at admission) and $319 \pm 23.85 \mathrm{IU} / \mathrm{L}$ (for median blood activity across the target group at discharge).

Comparison of the mean serum concentration of MPO, regardless of the time of collection / determination, but also of the calculated lot for the whole lot, shows net increases higher than both the normal circulating value and those determined in the group consisting only of patients with ischemic cardiopathy:

- the mean serum concentration on the entire target group was $351 \pm 24.75 \mathrm{IU} / \mathrm{L}$ versus the mean serum concentration on the whole control batch: $293 \pm 22.45 \mathrm{IU}$ / L;

- serum mean activity on the entire target group at admission: $383 \pm 14,25$ IU / $L$ versus mean serum activity on the control group at admission: $298 \pm 17.51 \mathrm{IU} / \mathrm{L}$;

- mean blood concentration on the whole target group

\footnotetext{
*email:dr.tudor@gmail.com
} 
at discharge: $319 \pm 23.85 \mathrm{IU} / \mathrm{L}$ vs. mean serum discharge at baseline, within the case of the same control group: 258 $\pm 24.75 \mathrm{UI} / \mathrm{L}$.

Comparison of the mean serum MPO values determined in patients with heart failure with those of the same parameter, but determined in the group formed only by patients with ischemic cardiopathy, we considered necessary because the action developed by myeloperoxidase in the pathogenesis of cardiac insufficiency seems to be at the level of inter-causal link coronary artery plaque vulnerabilityand remodeling of the left ventricular myocardium [6].

The result of the comparison highlights the increase of the mean serum concentration of MPO in the determinations performed in the group consisting of patients with heart failure, by $22 \%$ above the mean serum level determined at the level of the control group, formed only by sufferers with chronic ischemic heart disease.

The values of our determinations presented in the previous figure are in line with those of other similar studies.

The study of the mean serum concentration of MPO in the target group in relation to the systolic volume showed values approximately equal to the average for the whole group, regardless of which subgroup the patients belonged to:

- mean MPO serum activity on the target group: $351.70 \pm$ $24.75 \mathrm{IU} / \mathrm{L}$;

- for the mean serum MPO concentration on sublot I: $359.36 \pm 12.44 \mathrm{IU} / \mathrm{L}$;

- for the mean serum MRL concentration on the sub-lot II case: $344.44 \pm 21.28 \mathrm{UI} / \mathrm{L}$.

The data presented allow us to argue that in circulatory insufficiency the circulating level of MPO increases significantly in the disease but is not dependent on the systolic flow rate.

Studying within each sublot the mean serum concentration and its correlation with the ejection fraction found that serum MPO serum concentrations in both subparts are increased well above normal compared to serum normal but slightly higher for the value calculated in the subgroup of patients with heart failure and conserved systolic flow.

Our data are coordinated with the results of numerous international studies that confirm that in circulatory insufficiency the circulating level of MPO is increased, correlating with the degree of ejection fraction reduction or the plasma concentration of natriuretic peptide B. $[7,8]$.

Although in the research literature we have notidentified an explanation of such a behavior of myeloperoxidase, we consider as a possible explanation the responsibility of reducing the systolic flow through both the cardiac and the cardiac, which affects secondary irrigation of all tissues, reducing it. As a result, the reduction in tissue levels of both nutrients and oxygen intake generates metabolic disturbances with the exacerbation of oxidative radical production. In a subsequent step, exacerbation of ROS / RNS becomes an activator of the sources of MPO release in the blood, i.e., augmentation of the serum activity of this enzyme, a marker of chronic inflammation.

By comparing the MPO mean concentration values at discharge to the two target subpopulations, we found that for caseus patients with reduced ejection fraction cardiac insufficiency, these were reduced but much less than in cases of congested heartfailure. These increases are nearly $7 \%$ in favor of low-ejection fraction.

We interpret the reduction in the mean serum concentration of MPO at discharge compared to the discharge value as the expression of statin therapy that the patients received. In this regard, we mention as an argument the many international studies that admit that statin administration induces a beneficial effect in heart failure therapy, regardless of LDL level. This is because according to Kumar A.P. and so on, statins would suppress the expression of MPO actions, thus influencing the development of ROS / RNS-enabled pathways [9]. In support of such action, the results of Shishehbor M.H. etal. which showed that statins have the ability to modulate RNS action, relying on highlighting reductions in circulating nitrotirozine levels in patients with heart failure and statins [10].

The current state of knowledge regarding the value of myeloperoxidase as a cardiac failure biomarker admits that myeloperoxidases (MPO), although derived from leucocytes, were first reported to have increased serum levels in human heart failure in 2006, by the team of researchers led by Tang WH Moreover, the study revealed a correlation between blood levels of myeloperoxidases and natriuretic atrial BNP (BNP) with prevalence / association with ventricular myocardial contractile deficit. [11]. According to studies of the above-mentioned research team, elevated plasma levels of MPO translate clinically a severe impairment of the diastolic performance of the left ventricular myocardium and at the level of the disruption of systolic function [6]. More recent researches reconfirm and support the correlation of myeloperoxidase serum values with the severity of cardiac insufficiency, recommending it to be used in multimarker strategies still in the early stages. The contribution brought by myeloperoxidase as a component in multimarker complexes results from at least two beneficial effects whose carriers are its circulating values:

a.Improving the predictive value itbrings to intermediate levels elevated by NT-proBNP [12].

b.Also, the fact that serum levels of myeloperoxidase appear to be independent of those of other markers of the inflammation, which is still incompletely exploited.

In our study, the mean serum concentration of myeloperoxidase compared to normal was increased both in ischemic cardiopathy and in that which produced congestive heart failure, its values increasing net when the myocardial myocardial myocardium passes to the myocardial contractile deficit, possibly to be highlighted by clinic-paraclinical means. Thus, if the mean serum concentration of myeloperoxidase in the control group was $293 \pm 22.45 \mathrm{IU} / \mathrm{L}$, in heart failure the values increased to an average of $308 \pm 24.75 \mathrm{IU} / \mathrm{L}$; increases are clearly superior in the subgroup formed by heart failure patients with the preserved ejection fraction $(319 \pm 23.85 \mathrm{lU} / \mathrm{L})$ compared to the determined value, respectively calculated as mean in the subgroup of patients with cardiac insufficiency with ischemic heart disease low systolic blood flow (383 $\pm 14.25 \mathrm{IU} / \mathrm{L}$ ).

If we admit that lowering the ejection fraction to the same etiologic type of heart failure translates from a myocardial level to a more pronounced reduction in myocardial contractility compared to cardiac insufficiency with conserved systolic blood flow, the serum concentration of myeloperoxidase in sublot II becomes serum biological expression of the existence of a higher myocardial contractile deficit, correlating with the functional deficitclass assessed by the NYHA classification criteria.

To explain this, starting from the action of myeloperoxidase family enzymes to intervene in the process of remodeling the myocardium and especially the 
fibrosis, we hypothesize the possibility that this latter process is one that increases in intensity, in cases of reduced heart rate with low systolic blood flow. This indirectly implies that in the cases of contractile myocardial deficiency with a preserved ejection fraction, the remodeling process is still active, decreasing in cases with low systolic volume, in which case the fibrosis is augmented.

Our findings are in line with those of Andreou I et al. which on 60 cases found on the one hand that the plasma level of myeloperoxidase is higher in patients with lowejection fraction with cardiac insufficiency and on the other hand that correlation between the serum concentration of myeloperoxidase and the functional deficiency class myocardial contractile [14-18]. Similarly, based on more recent studies by Tang $\mathrm{W}$. $\mathrm{H}$ et al., Elevated serum concentrations of myeloperoxidase are correlated with the functional deficitclass of heartfailure evaluated after NYHA classification [11, 19-23].

The high incidence of elevated mean serum concentration and MPO stagnation in cardiac failure cases is an additional argument, along with the hyper-MPOemitting value, that allow the dosage of circulating enzyme to be a biomarker for this disease. In order to explain the persistence of elevated serum concentrations of MPO in patients with heart failure and when it is in the final stages of evolution, we start from the action that the enzymes of the myeloperoxidase family develop, intervening in the remodeling process of the myocardium and especially fibrosis. This requires admitting that in the final stages of evolution of cardiac insufficiency although the process of myocardial remodeling diminishes, the associated fibrosis increases in intensity at both myocardial and other organs / tissues whose microcirculation is deficient due to the reduction of the flow rates of the organ, which require metabolism to occur at nutritional and oxygen deficiency conditions, leading to an excess of ROS / RNS synthesis.

The cases in the target group with an increase in MPO serum mean concentration, relative to the ejection fraction, were distributed by almost 13\% (12.8\%) more in the systolic flow reduction sublot. The existence of such a correlation is one of the arguments that can argue that the circulatory level of MPO in heart failure correlates with the meaning and degree of evolution of systolic flow.

In relation to the ejection fraction, basically with the type of heart failure of the patients, the positive results for the target sublot I of $10 \%$ and for the target sublot II were $11 \%$ of the whole lot. The rate of reduction of the mean serum MPO increases in the patients of the two sub-classes is equally sensitive, it allows to conclude that irrespective of the ejection fraction, therapy and lifestyle in cardiac insufficiency affects only a very small proportion of serum pro-inflammatory myeloperoxidase.

The comparison of these positive results, expressed in percentage terms, allows us to assert that sex is a factor influencing the evolution of the serum level of myeloperoixdase. We support this view because, both at admission and discharge, the incidence of cases with MRO serum increase was increased differentially, being almost double for males versus females. The diminishing of the biomarker activity in women in a 3-fold lower percentage than in the case of male patients tends to admit that the results of the therapy established in heart failure are dependent on the endocrine terrain of the patient. In order to interpret the findings, as well as the scientific supposition mentioned, we hypothesize that the response to treatment in heart failure in women may occur with some delay or even difference, being one not only slow but even worse, from an evolutionary point of view. We reiterate that these are only a possible hypothesis, because the positive response, somewhat too much obtained in the case of male patients, in a relatively short time of only 2 weeks of therapy requires the study to be expanded with the extension of the period of therapy, to track the evolution of myeloperoxidase serum concentration in patients with heart failure for a long time.

\section{Conclusions}

It has been shown that as the systolic volume decreases, the circulating level of the marker enzyme, while remaining high, tends to decrease.

We interpret this particular behavior of the circulating level of the MPO as a scientific argument that in patients with heart failure and reduced systolic flow, the circulating level of the enzyme, although increased, undergoes concordant modification (in the same sense) with the reduction of the ejection fraction constituting -a risk biomarker for this type of myocardial contractile deficit.

\section{References}

1. MALLE E., MARSCHE G., PANZENBOECK U., SATTLER W. Myeloperoxidase mediated oxidation of high-density lipoproteins: fingerprints of newly recognized potential proatherogenic lipoproteins. Arch. Biochem. Biophys., 2006, 445,(2), pag. 245-255

2. WILSON TANG WH, TONG W., TROUGHTON RW, MARTIN G.M., SHRESTHA K., BOROWSKI A., JASPER S., HAZEN L.S, KLEIN L.A.,Prognostic value and echocardiographic determinants of plasma myeloperoxidase levels in chronic heart failure. J Am Coll Cardiol., 2007,49, (24), pag. 2364-2370

3. BALDUS S, HEESCHEN C, MEINERTZ T et all. - Myeloperoxidase serum levels predict risk in patients with acute coronary syndromes. Circulation 2003;108, pag.1440-1445).

4. PRASAD K., KALRA J., MASSEY K.L., BHARADWAJ B.- Increased production of oxygen free radicals by polymorphonuclear leukocytes in heart failure due to aortic stenosis. Angiology, 1989, 40, pag. :472478;

5. PRASAD K, KALRA J , BHARADWAJ B. - Increased chemiluminescence of polymorphonuclear leucocytes in dogs with volume overload heart failure. Br. J. Exp. Pathol., 1989, 70, pag.: 463- 468

6. TANG W.H., TONG W., TROUGHTON R.W., MARTIN G.M., SHRESTHA K., BOROWSKI A., JASPER S., HAZEN L.S., KLEIN L.A. - Prognostic value and echocardiographic determinants of plasma myeloperoxidase levels in chronic heart failure. J. Am. Coll. Cardiol., 2007, 49, (24), pag. : 2364-2370

7. ABU-SOUD H.M., HAZEN S.L. - Nitric oxide modulates the catalytic activity of myeloperoxidase. J Biol Chem 2000;275:5425- 5430;

8. NG LL, PATHIK B, LOKE IW, SQUIRE IB, DAVIES J.E. - Myeloperoxidase and $\mathrm{C}$-reactive protein augment the specificity of B-type natriuretic peptide in community screening for systolic heart failure. Am Heart J., 2006, 152, pag. : $94-101$

9. KUMAR AP., REYNOLDS W.F.- Statins downregulate myeloperoxidase gene expression in macrophages. Biochem Biophys Res Commun ., 2005, 331, pag.442-451

10. SHISHEHBOR M.H., AVILES R.J., BRENNAN ML., et al. - Association of nitrotyrosine levels with cardiovascular disease and modulation by statin therapy. JAMA, 2003, 289, pag.1675- 1680

11. TANG W.H., BRENNAN M.L., PHILIP K. etall.- Plasma myeloperoxidase levels in patients with chronic heart failure., Am. J.Cardiol., 2006, 98, (6), pag.: 796-799

12. MICHOWITZY, KISIL S, GUZNER-GUR H. et all. - Usefulness of serum myeloperoxidase in prediction of mortality in patients with severe heart failure., I.M.A.J., 2008, 10,pag. 884- 888

13. SINNING C, SCHNABEL R, PEACOCK F, BLANKENBERG S. - Upand-Coming Markers: Myeloperoxidase, a Novel Biomarker Test for Heart Failure and Acute Coronary Syndrome Application?, Heart Failure, 2008, 14, (4), pag.: 46-48 
14. ANDREOU I., TOUSOULIS D., MILIOU A., TENTOLOURIS C., ZZZIMIS K., GOUNARI P., SIASOS G., PAPAGEORGIOS N., PAPADIMITRIOU C.A., DIMOPOULOS M.A., STEFANADIS C.,Effects of rosuvastatin on myeloperoxidase levels in patiens with chronic heart failure: a randomized placebo-controlled study: aterosis, 2010, 210. pag. 194198, abstract

15. BALAET C., COCULESCU B.I, BALAET M., MANOLE G., DINCA V.G. - Haemolytic anaemia and hepatocitolysis associated with hypermagnesaemia by repeated exposures to copper-calcium fungicides. J. Enzyme Inhib. Med. Chem. 2018, 33(1):184-189.

16. BALAET C., COCULESCU B.I, MANOLE G., BALAET M., DINCA V.G., Gamma-glutamyltransferase, possible novel biomarker in colon diverticulosis: a case-control study. J. Enzyme Inhib. Med. Chem. 2018, 33(1): 428-432.

17. COCULESCU B.I., MANOLE GH., DINCA V.G., COCULESCU C.E., BERTEANU C., STOCHECI M.C., Osteopontin-a biomarker of disease, but also of stage stratification of the functional myocardial contractile deficit by chronic ischaemic heart disease - Journal of Enzyme Inhibition and Medicinal Chemistry - ISSN: 1475-6366; Volume 34, 2019, Issue 1; pg. 783-788

18. COCULESCU B.I, DINCA V.G., BALAET C., MANOLE G., BALAET M., STOCHECI C.M. - Myeloperoxidase, a possible biomarker for the early diagnosis of cardiac diastolic dysfunction with conserved ejection fraction. J Enzyme Inhib Med Chem. 2018, 33(1):1292-1298.
19. COCULESCU, B.I, DINCA, V.G., MANOLE, G., PURCAREA, V.L., STOCHECI, C.M., Serum concentration of hsCRP - possible marker for therapy evaluation in left ventricular dysfunction with preserved ejection fraction - Rev.Chim. (Bucharest), 69, no.10, 2018, p.28852890.

20. DINCA, V.G., MANOLE, G., COCHIOR, D., DINCA, A.L., Growth differential factor 15 (GDF-15), possible biomarker in heart failure, Rev.Chim.(Bucharest), 68, no. 3, 2017, pg.631-634;

21. DINCA, V.G., MANOLE, G., COCHIOR, D., DINCA, A.L. ,Paraoxonase (PON1) possible biomarker for risk of heart failure, Rev. Chim.(Bucharest), 67, no. 5, 2016, p.854-857

22. CAPITANESCU C., MACOVEI OPRESCU A. M., IONITA D., DINCA G.V., TURCULET C., MANOLE GH., MACOVEI R. A. - Molecular process in streptokinase thrombolytic therapy - Journal of Enzyme Inhibition and Medicinal Chemistry - ISSN: 1475-6366; Volume 31, 2016 - Issue 6; pg. 1411-1414;

23. DINCA V.G., MANOLE G., Organ failure as an expression of organ remodeling. Involvement of oxidative stress - J ournal of Medicine and Life ISSN 1844-122x; 2013; Volume 6, Issue 3, July-September; pg.240-243.

Manuscript received: 25.02 .2019 